\title{
Assessment Practices in the Center for Regional and Local Development Studies, College of Development Studies in Addis Ababa University, Ethiopia
}

\author{
Ephrem Ahadu \\ Department of Civics and Ethical Studies, Wachemo University, Po box 667, Hosaena, Ethiopia
}

\begin{abstract}
This research investigates instructor's assessment practices in the center for RLDS, college of development studies in Addis Ababa University. The samples used for the study consisted of 5 teaching staff (those who thought first and the second year students in 2018/19 academic year), and 17 students from both academic years are randomly selected. In addition, the student's evaluation results of 4 courses, 2 instructors and 6 students randomly selected for document review and interview respectively. The instrument used for this study were closed ended and open ended questionnaires, an interview and document analysis. The data were analyzed using simple descriptive statistics like percentage and mode as well as the mean scores. The paper tries to give the general over view of how instructors evaluate their student's academic performance, the criterion and guidelines they used to select a given assessment methods, the effectiveness of their assessment practices to measure the three domains of learning of their students and the assessment methods the instructors in the center used frequently as well as which of these method the students more prefer. The major findings of the study is that, in the center for RLDS, the assessment practice is of summative paper-pencil based used only for grading not for students learning, even though some instructors used course objective as their criteria, there is no general assessment guidelines and criterion used by instructors to select a given assessment method, mark and grading, and the instructors do so arbitrarily and very differently. The frequently used assessment method is assignment and final exam that given for students at the end of the courses while the students prefer assignment, mid exams and final exam that given at different times during their learning. The paper also finds out that there is significant variation among instructors depending on their service year and academic rank in using assignment and final exams. Thus, as the academic rank and service year increases the inclination of instructors to use one or two assessment at the end of the course increases. Finally the study discovered that most students distrust their instructors during evaluation due to the lack of responsibility and accountability on the parts of instructors on marking, grading and letting students to check their results.
\end{abstract}

Keywords: Assessment, practice, evaluation, RLDS

DOI: $10.7176 / \mathrm{JEP} / 10-4-02$

\section{INTRODUCTION}

\subsection{Background of the Study}

In Ethiopia, secular higher education was initiated only in 1950 with the founding of the University College of Addis Ababa. During the following two decades, half a dozen specialized technical colleges were established, and by 1970 tertiary enrolments totaled 4,500 out of a national population of 34 million indicating the tertiary enrolment ratio of 0.2 per cent was among the very lowest in the world (FDRE, 1994). Contemporarily, in the context of massification of higher education in the country, According to the report of ministry of education, total tertiary enrolments in universities surged from 43,843 in 1998 to 147,954 in 2003, more than tripling in just five years with annual enrolment growth rate of 28 percent which was probably among the highest in the sub Saharan Africa (MoE 1998, 2003).

Nevertheless, with such massification of universities, Ethiopia found herself with a higher education system that was regimented in its management, conservative in its intellectual orientation and limited in its autonomy, causing the quality of higher education of the country to be questioned (MoE, 2003). According to (Yizengaw 2003), in addition to shortages of experienced professors among academic staff, weak research output and the poor connection with the intellectual currents of the international higher education community, the poor quality of Ethiopian higher education assessment system seriously commented as a causes of declining educational quality of the country at tertiary level.

Many literatures further elaborated that with the increasing number of universities and students enrollment, particularly, the issues of assessment at graduate level started to directly relate to the quality of education. Accordingly, since 1994 when the country launched its comprehensive national educational policy, the issue of assessment was able to be a priority agenda of stake holders including government as a precondition to bring educational quality of higher educations (FDRE, 1994).

The New Education and Training Policy gave emphasis on the use of continuous assessment at both graduate and undergraduate level, aiming to bring a paradigm shift from old aged traditional system of assessment that is a judgmental role in its orientation to developmental role (Gemechu, 2013). Hence, the new education and training 
policy of the country calls for the use of continuous assessment to realize the educational objectives. However, despite the importance of the proper implementation of continuous assessment, it might not go beyond lip service particularly at graduate level. Therefore, assessing the status of the practice of assessment at graduate level is found to be very crucial.

\subsection{Statement of the Problem}

Major changes in the area of assessment of learning, students' progress and achievement have taken place worldwide. Consequently, the assessment policy of Ethiopian higher education institutions has been reformed to respond to this global development. The policy stipulates that continuous assessment should be employed to ascertain the formation of all rounded profile of students at all levels (TGA, 1994). The main purposes of using this mode of assessment are to develop students' abilities over time and to judge their performance based on the data obtained from the continuous assessment and final examination.

Observations and experience, however, seem to inform us that there are problems associated with the implementation of continuous assessment. Unlike the educational policy and strong advocacy about the importance of this mode of assessment by institutional leaders, some instructors are observed complaining about practical issues related to this assessment mode. Large class size and heavy teaching load in a semester are some of the factors for instructors' resistance to effectively and efficiently implement continuous assessment. There also seems to be a knowledge gap to clearly understand how continuous assessment is benefiting the teaching learning process in contexts where the majority of the instructors are mainly subject specialists with no or very little training on pedagogy.

The teaching and learning process needs continuous follow up to achieve its objectives. Hence continuous assessment is essential to check the realization of instructional objectives. Traditional assessment method mainly focuses on testing which encourages superficial learning, but did not assess the wider skills of pupils. Hence, continuous assessment should be essential to measure learners' performance in a holistic manner. There might be changes to better or the worse. This creates a researcher a curiosity to investigate the status of the assessment practices of instructors in center of RLDS in College of Development Studies of Addis Ababa University.

\subsection{Research Questions}

The study attempted to investigate and answered to the following research questions:

$>$ Is there a general assessment guideline formulated by Addis Ababa University to be used by instructors?

$>$ Does RLDS instructors' refer to this guideline in assessing their students?

$>$ What techniques are mainly practiced by instructors to assess their students?

$>$ Do the techniques used by instructors sufficient to measure the performance of their students?

$>$ What could be done so as to alleviate problems assessment that existed at the center for RLDS?

\subsection{Objectives of the Study}

\subsubsection{General Objective}

The main objective of this paper is to review the assessment practices used by the center of RLDS of the College of Development Studies of the Addis Ababa University.

\subsubsection{Specific Objectives}

Specifically the study was aimed to:

- To review whether there is any assessment guideline used mainly for the assessment of students

- Assess the sufficiency of assessment guideline to enable instructors in the center to evaluate their student's performances

- To investigate the frequently used assessment techniques in the center by instructors to assess the academic performances of students

- To evaluate sufficiency of techniques used by instructors in assessing of the performance of their students

- To suggest some alternatives for the problems raised on issues of assessment of students

\subsection{Significance of the Study}

The results from this study would add to the existing literature on classroom assessment practices. This study focused on assessment practices that teachers used every day in the classroom to collect information in order to understand the learning difficulties of the students. It is hoped, therefore, that this study added a different dimension to literature on classroom assessment.

In general the findings of this study might contribute in the following ways:

$>$ The research results would inform instructors and learners about the significances and status of assessment practices being utilized in center of RLDS.

$>$ The paper would provide relevant knowledge and information to the center of RLDS about the status 
instructor's assessment practices.

$>$ Teachers would be informed of the alternative assessment techniques that could be used to enhance student performance.

$>$ This paper could be used as a foundation for further research that will benefit other researchers to do their research in these areas.

\subsection{Scope of the Study}

The study was made only in the center for RLDS in College of Development Studies of the Addis Ababa University. The major emphasis of the study was on the assessment practices of instructors used mainly in evaluating of students performance in this center. The study also covered only first and second year's students and instructors who have given the course for these students in 2018/09 academic year.

\subsection{Limitation of the Study}

The serious limitation of this study is the problem of accessibility of data. On part the instructors, unwillingness to fill questionnaires and respond to interviews assuming that the researchers going to disclose their views and even work. On the hands difficulty of students particularly year two students for most of these students already went to the field for data collection to their graduation thesis. Another limitation related to data is that difficulty of accessibility of documents like student's assignment and exam papers for review.

Another limitation is that in addition to the time needed to complete the work, the finance needed is not enough. As a result these limitations and others compel the researchers to minimize the sample size which in turn may minimize the representativeness of the sample.

\section{REVIEW OF RELATED LITERATURE}

\subsection{Definitions and concepts}

\subsubsection{What is assessment?}

There is no single precise definition for the term assessment. But there are various meanings given by different scholars at different times, however, these definitions are more or less similar. Airasian, among others, defined assessment as the use of empirical data on student learning to refine programs and improve student learning (Airasian, 1991).

Assessment is also defined as the process of gathering and discussing information from multiple and diverse sources in order to develop a deep understanding of what students know, understand, and can do with their knowledge as a result of their educational experiences (Wittrock, 1986).

Assessment is the systematic basis for making inferences about the learning and development of students. It is the process of defining, selecting, designing, collecting, analyzing, interpreting, and using information to increase students' learning and development (Ellington, 1997). It is the systematic collection, review, and use of information about educational programs undertaken for the purpose of improving student learning and development (Cain, 2012).

Accordingly, assessment is an integral component of learning and teaching. It refers to all processes employed by academic staff to make judgments about the achievement of students in units of study and over a course of study. These processes include making decisions about what is relevant evidence for a particular purpose, how to collect and interpret the evidence and how to communicate it to intended users (students, parents, university and administrators). Therefore, Assessment is an integral part of instruction, as it determines whether or not the goals of education are being met. Assessment affects decisions about grades, placement, advancement, instructional needs, curriculum, and, in some cases, funding.

\subsubsection{What are the purposes of Assessment?}

Assessment is used in education to refer to any procedure or activity that is designed to collect information about the knowledge, attitude or skills of a learner or group of learners (Kellaghan and Greaney, 2004). Accordingly, teachers who collect this information on students' performance want to make sure that the information they collect actually reflects where students are in respect to an intended outcome. Assessments are key components of all education systems and play a critical role in a students learning journey. By measuring student achievement and skill mastery, assessment helps students learn, teachers improve instruction, administrators decide how to allocate resources, and policy makers evaluate the effectiveness of educational programs.

In connection to this point, (Abera, 2012), identifies the following purposes of assessment.

1. Student Learning: Assessment is a way for educators to measure progress, strengths, and areas of growth of students. Many teachers assess their students using a pre-test, mid-term, and post- Test to gauge student learning. 2. Improvement of Teaching: Teachers use assessment to determine what is effective in their teaching practices; what is working and what needs improvement. A variety of assessment tools may be used in order to determine what types of instruction are most beneficial in meeting the needs of students.

3. Communication: Assessment should serve as a means of communication between educators, students, 
administrators, and parents. Parents and students often look at assessment to see what is being learned, how progress is being measured, and the type of instruction being received. Educators and administrators use assessment to evaluate teaching practices and to determine if there are gaps in the curriculum.

4. Program Evaluation: Assessment can prove a good measure of one's program, revealing evidence of the effectiveness of that program. Throughout the year, assessment can offer direction to the program and modifications can be made to increase both student and Instructional success.

5. Program Support: Consistent assessment can be used to validate one's program. Data gained is objective and can show evidence of goals and objectives being met by both student and teacher. With clear data presented, a strong measure of program support may follow.

6. Motivation: Assessment shows progress. When improvement is shown, students feel positive about their learning environment. Documented assessment can offer proof of growth, thus enhancing students' motivation to perform to the best of their ability.

\subsubsection{Types of Assessment}

We have different types of assessment technique used by different countries and educational institutions. Continuous assessment (formative assessment) and Summative assessment are the common types of assessment.

\subsubsection{Continuous Assessment}

Different writers define continuous assessment differently. Some definitions confine continuous assessment only to classroom instruction. Asabe (2007), for example, defines it as a classroom process that is integrated with instruction. Similarly, Falayalo (1986) and Juliet (2007) viewed it as an integral part of instruction, and as a mechanism whereby the final grading of learners on the cognitive, affective, and psychomotor domains of learning is made. Continuous assessment is a classroom strategy implemented by teachers to ascertain the knowledge, understanding, and skills attained by students (USAID, 2003). Nitko (2004), as cited in Adebowale and Alao (2008), described it as an information gathering tool that helps teachers select content and method of instruction. Therefore, continuous assessment is an ongoing process of gathering and interpreting information about student learning that is used in making decisions about what to teach and how well students have learned.

Other literatures see continuous assessment as related to and beyond classroom instruction. For example, Asabe (2007) envisaged it as a decision-making tool that teachers utilize about students, curriculum, programs, and educational policy. Many, however, agree that it is a process of collecting, interpreting and synthesizing information to aid decision-making. Continuous assessment occurs recurrently during the school year, and serves as a part of teacher-student interaction. It serves as a means of increasing students' achievement, and is used as an alternative or supplemental to high stake testing (USAID, 2003). As divergent from summative tests, continuous assessment is formative in that it enables both teachers and students to be aware of the knowledge base and level of students, and indicates both teachers and students the gaps to be filled and the higher level to deal with.

To sum up, there are a lot of terms that can be used to describe Continuous assessment. In some countries, people refer continuous assessment as running records, or curriculum based assessment. Sometimes, it referred as formative assessment. In all cases, teachers are given the responsibility to find out what students in their classes know, understand and are able to do. When a variety of ways over time used to improve instruction, then it is considered to be Continuous assessment (Joy, 2003 as cited in Tamene, 2007).

\subsubsection{Summative assessment}

According to Brown and Knight (1994), summative assessment “ produces a measure which sums up someone's achievement and which has no other real use except as a description of what has been achieved'. This summative description, however, could be used to evaluate "the effectiveness of programs, school improvement goals, alignment of curriculum, or student placement in specific programs" (Garrison and Ehringhaus, 2007). Summative assessments which are conducted at a particular point in time, usually at the end of a course, or a program, are far away to provide information that can be used during the teaching and learning process. The following list presents instances of summative assessments. State assessments, district benchmark or interim assessments, end of unit or chapter tests, end of term or semester exams, scores that are used for accountability for schools and students (Tertiary Educ. Manage, 11:219-238).

Describing summative assessment by analogy, Black (1998) in Swearingen (2002) said "when the cook tastes the soup, that is, formative assessment, when the customer tastes the soup that is summative assessment". Thus, one could safely say that the focus of summative assessment is to judge achievement after completing a certain program while that of formative or continuous assessment is to develop students' learning.

\subsubsection{Assessment of bench marks}

Grades to students' performance could be awarded using different bench marks. Two of these include norm referenced and criterion referenced. Both of them distinctively differ in their ways to process assessment data and judge level of achievement (Aytaged, 2010).

\subsubsection{Norm referenced Assessment}

The major purpose of using norm referenced assessment is to pass decisions about students' achievements by determining individual performance in comparison to others. Complementing this purpose, Bond (1996) quoting 
Stigens (1994) says that norm referenced assessment is used "to produce a dependable rank order of students across a continuum of achievement from high achievers to low achievers". He also went on saying that such classification of students into their level of achievements can help to place them either into a remedial or gifted program. On the other hand, Dunn et al. (2002) con-tended that norm referenced assessment "says very little about the nature or quality of teaching and learning, or the learning outcomes of students".

\subsubsection{Criterion referenced Assessment}

The aim of criterion referenced assessment is to identify what each student knows, understands and can do in light of a well-defined criterion (Bond, 1996). It, however, does not focus on comparing students on their achievements. Elaborating the purpose of criterion referenced assessment, Bond (1996) stated that it reports "' how well students are doing relative to a pre-determined performance level on a specified set of educational goals or outcomes included in the school, district, or state curriculum". Since individual performance is compared to some set standards or criterion, competition among students is not emphasized. One of the criticisms of this assessment as pointed out by Rowntree (1987) cited in Dunn et al. (2002:3) is that if students do not compete "academic rigor will be lost".

\subsubsection{Methods of assessment at higher education in Ethiopia.}

The assessment of students at the university level is variable from country to country and also among the universities within a country. Several factors play a role in achieving the goal of human resource development, among these, the assessment method followed by the universities, is the most important one. Assessment informs how well the students learn and how well the instructor is teaching. Consequently, the assessment policy of Ethiopian higher education institutions has been reformed to respond to global development. This is clearly spelt out in the Education and Training Policy of the country for the policy stipulates that continuous assessment should be employed to ascertain the formation of all rounded profile of students at all levels (TGA, 1994). The main purposes of using this mode of assessment are to develop students' abilities over time and to judge their performance based on the data obtained from the continuous assessment and final examination. Furthermore, Continuous assessment enables teachers to develop students' psychological, intellectual, physical and social interaction skills.

\subsection{Challenges of Continuous Assessment in higher Education}

The history of assessment shows a long line of structural changes designed to inject quality control into education. It uses a testing system which is designed to measure students' performance and hold school accountability. In line with this argument, Rink (2006:57) asserted,

"One of the recent directions of educational reform has been the emphasis of assessment in the teaching learning process."

Various studies both in Ethiopia and abroad were conducted on different issues about assessment practices especially about continuous assessment. For instance, Kapambwe (2010) studied teachers' implementation of continuous assessment in Zambian schools at length. His findings indicated that teachers emphasized continuous testing instead of continuous assessment. Kapambwe assumed that this happened because of the past influences of traditional objective-based assessment. Owolabi and Onuka (n.d.), on the other hand, found the challenges of using continuous assessment in Nigerian universities to be students' inadequate preparation for assessments, teachers' poor test administration procedures, poor handling of scores and feedback, poor coverage of instructional contents by test contents, large classes, and lack of knowledge and skills of the appropriate evaluation techniques. Obioma (n.d.) disclosed that teachers in Nigeria lacked knowledge of continuous assessment, and instead gave continuous testing. Plessis (2003) as cited in Muluken (2006) pointed out that assessment as a system appears to rest on a well- considered theoretical underpinning and there are major short comings at the practical implementation level. As such, the current assessment and monitoring procedures and practice do not seem to contribute and inform classroom practices as optimal as originally intended. Of course, teachers face challenges while they assess students for they have not enough access to the type of assessment information that will enable them to carry out the assessment accurately and fairly. In conformity to this, Brown and Knight (2010) disclosed that most teachers feel unprepared to assess in the way the institution or the department requires them to do. They further continued, for instances, on to argue, "Most teachers use the same type of assessment techniques, especially their teachers used while they were at school". Beside this, most teachers tend to focus their assessment strategies on what is easy to measure rather than on what is important.

In Ethiopia, Tebeje (2009) reported that instructors and students had inadequate knowledge of continuous assessment. Instructors consider it as an extra work load, which might be interpreted as a negative attitude towards it.

By considering all the studies above it is safe to say that successful implementation of assessment demands more work, time and responsibility on the part of teacher. If the teacher is not adequately prepared for operating the system, it may lead to a tendency to cook up scores in the name of assessment. 


\section{METHODOLOGY}

\subsection{Study Institution Setting}

The study is conducted in the Center for regional and Local Development Studies, one of the programs given at masters' level in the College Development Studies found in Akaki Campus, of Addis Ababa University, which is the largest and the first Government University in Ethiopia. The center has been set up jointly by Addis Ababa University (AAU) ${ }^{1}$ and the Institute of Social Studies (ISS) in The Hague, The Netherlands in 1996 as a part of the AAU/ISS ${ }^{2}$ Project entitled "Capacity Building for Training and Policy Research in Regional and Local Development Studies in Ethiopia," being funded by The Netherlands Ministry of Development Cooperation until 2004. According to the profile of the center found on Addis Ababa University Website, the general objective of the center is to produce highly qualified persons in the fields of Regional and Local Development, who will be competent in promoting and managing socio-economic development at sub national levels in Ethiopia, through the development of interdisciplinary education and research. The Center also has a vision of expanding the program to development studies for the countries in the Horn and Eastern Africa to be the center of excellence in the region.

Starting from its set up to 2013, the center able to graduated many students in regular program and currently 33 students are enrolled in the program which of 12 are first year students. Currently the center has 12 staffs of which 2 are expatriates professors and 4 supportive staffs that are executing the activities both teaching learning and administrative matters of the center.

\subsection{Sampling Techniques and Procedures}

The study institution is selected purposively mainly because the researchers are first year students who are currently following their education in this institution which made data collection easy. The population of the study is drawn from instructors and students in the center. For questionnaires, a total of 5 instructors and 17 students were taken from the center using simple random sampling technique by resorting to a random digit table. This has done by collecting the available names of academic staff members who have given the course for students of the center in academic year 2018/09 as well as lists of students of the center in the same academic year from the secretary of the sector. In addition, from these lists two instructors and six students identified randomly using random digit table for interviews.

Further, the simple random sampling technique supported by random digit table was also used to select and to review the student's evaluation result of several courses submitted by different instructors. Accordingly, the student's evaluation results of 4 courses were selected for review. Nevertheless, due to accessibility constraints only student's evaluation result of 2018/09 academic year were reviewed.

\subsection{Data collection instruments}

As both qualitative and quantitative study, the major data collection instrument used was questionnaires, document review and an in-depth interview with instructors and students.

\subsubsection{Questionnaires}

Both close and open-ended questionnaires were administered for students who were enrolled in 2018/09 academic years in focus to gather data on their perception of how instructors practice classroom assessment and instructors those gave the course for students of the center to know their perception about the classroom assessment they used. A total of 17 perception items for instructors and 10 perception items for students were developed and used in this study. After conducting a pilot test to make the questionnaires is reliable and valid, the paper distributed to instructors and students. Accordingly, all sample students and instructors returned the correctly completed questionnaires.

\subsubsection{Desk Review}

Creswell (2009) highlights that desk review enable a researchers to obtain the language and words of participants, modest sources of information, for written evidence saves the time and expense of transcribing of a researchers. In light of this, documents (final exam papers, mid test papers, assignment papers and assessment modalities and guidelines) were employed to gather data pertinent to the study. Accordingly, all of the sampled course's student evaluation results were reviewed.

\subsubsection{Interview}

Many literatures confirmed that Interview is useful when participants cannot be directly observed, allows researcher control over the line of questioning, to attain higher response rates, to guard against confusing questionnaires items, it is the most flexible method, and helps to get answer to all questions (Creswell, 2009; Babbie, 1973; Neuman, 1994; Kumar, 1999; Kothari, 2004). Moreover, it is very good way of accessing people's perceptions, meanings, definitions of situations and constructions of reality as well as understanding individual or group perspectives (Punch, 1998).

\footnotetext{
${ }^{1}$ Represent Addis Ababa University

${ }^{2}$ Represent Addis Ababa University/Institute of Social Studies
} 
Thus, the researchers prepared an interview guide to focus on the discussion, make use of the limited time for the interviews, and systematically address issues relevant to the study. These guides also help us to conduct the interview only with one of our research group. Even though the guide predetermined the researchers focus, it did not do so whenever we wanted to probe and explore issues under this predetermined inquiry area and when interviewees raised related issues.

The study participants were asked for their willingness to be interviewed and the interviews were conducted on the pre- agreed schedule. The time taken in the interviews ranged from 30minute to 45 minute and all of them were conducted in quiet places. Even though caution has been taken to give much of the talking time to the interviewees and not to bias their responses by the interviewer's body gesture and facial expressions, but whenever some thoughts were not completely presented, seemed to be ambiguous and needed further discussion, the researchers asked for clarification, additional information, follow up questions and did also some probing. Accordingly all of the sampled instructors and students able to interviewed.

\subsection{Data Analysis Technique}

Since the research is of both qualitative and quantitative, the collected data also analyzed both qualitatively and quantitatively. Thus, data collected through interview, open ended questionnaires and through review of finale exam, mid exam and assignment papers are more of qualitative and narrated. Data collected through closed ended questionnaires as well as some data obtained from document review are quantified and analyzed quantitatively.

For quantitative data simple descriptive statistics such as mean values, percentage and mode are used and before analyzing the collected data, effective data entry tasks were done and the analysis tasks were performed with the help of SPSS Windows 21.

\section{RESULTS AND DISCUSSIONS}

The overall purpose of this research is to assess assessment practices used by instructors of the center of RLDS in the College of Development Studies of the Addis Ababa University. In addition to these general objectives this paper tried to identify how instructors select a given assessment method, how effective these assessment methods are in evaluating and facilitating students learning and which assessment methods most frequently used in the center in the academic year 2018/09. To realize this goal, the data were collected, organized and presented as follows.

\subsection{Assessment Practices of instructors in the center for RLDS}

Gemechu Abera (2013), in his assessment of factors affecting the implementation of Continuous Assessment in Rift Valley University College, listed assessment methods that should be used in higher education like universities including but not limited to Attendance, class participation, demonstrations, pencil paper exam, experiments, assignments, field works, group works, individual works and portfolio. Even though the use of these methods are varied depending on the nature of the course, teaching methods and educational level i.e., undergraduate and graduate, nevertheless these methods are common and should be used by instructors based on the situation to assure quality of education and facilitate student's learning.

Similarly, we have tried to assess the assessment practices of instructors in the center for RLDS of college of Development Studies in Addis Ababa University, and we found that very few of assessment methods that are listed to be used at higher education are used by instructors in this center. To this end the response of both students and instructors in the center signified that instructors only uses summative pencil-paper exam. The response from both instructors $\left(80 \%, \mathrm{~F}^{1}=4\right)$ and students $(94.1 \%, \mathrm{~F}=16)$ indicated that pencil-paper based exam dominated the assessment system of the center in the academic year 2018/09.

The research also found that in selecting any assessment method instructors neither have a look at any assessment guideline nor interest of their students. From the total sample respondents answer the question whether there is any guideline to observe when they assess their students, majority of them $(100 \%, \mathrm{~F}=5)$ responded that they are not sure for the existence of guideline prepared at university, college or in the center. Adding to this instructors respond that they never prepare any guideline for assessment for themselves and they simply decided arbitrarily, most of the time, to minimize their work load $(80 \%, \mathrm{~F}=4)$. The document reviewed, instructor's interview and student's response also supports this status quo. For example from total sampled students $(\mathrm{N}=17)$, majority of them $(88.23 \%, \mathrm{~F}=15)$ responded that assessment method marking among instructors is completely different, but if there may be assessment guideline that instructors referred, such huge difference could not be occurred. At the same time from the sample document reviewed absolute majority $(80 \%, \mathrm{~F}=4)$ of instructors assigned mark very differently for the assessment techniques and items of the questions most of which, they called it based on the course objectives, but very arbitrarily.

\footnotetext{
${ }^{1} \mathrm{~F}$ as it used many place, in data analysis and discussion parts, represents frequency of respondents: the number of respondents from total sample
} 
Some finding that is very similar with this is that, what criteria instructors in the center of RLDS used to select a given assessment method and evaluate their students. As the following figure clearly depicted, even though variation depending on the instructors years of services and academic rank exist, majority of instructors $(60 \%$, $\mathrm{F}=3)$ used course objectives while only small number $(40 \%, \mathrm{~F}=2)$ minimizing work load as a criteria to select a given assessment method.

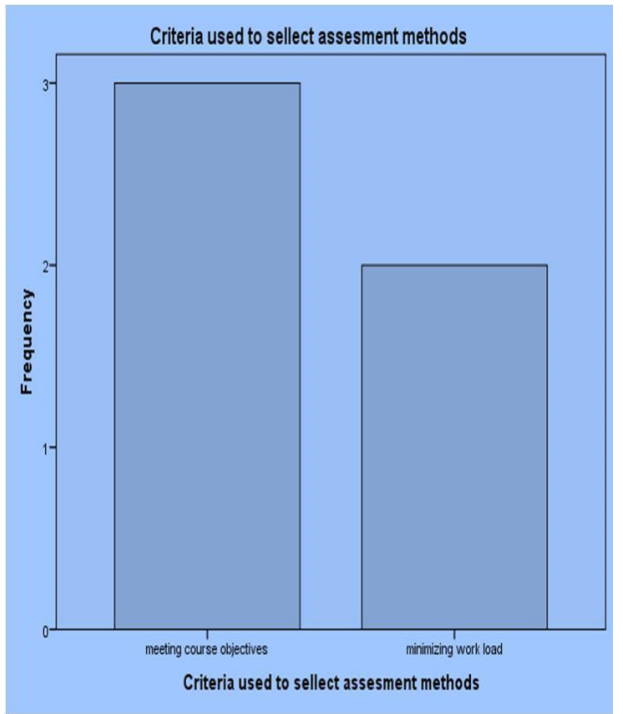

Figure 1: Criteria used by instructors to select a given Assessment methods.

Another finding of the assessment practices of instructors in the center was, the data show that as a principle instructors $(20 \%, \mathrm{~F}=1)$ strongly agree, $(40 \%, \mathrm{~F}=2)$ agree, $(20 \%, \mathrm{~F}=1)$ dis agree and $(20 \%, \mathrm{~F}=1)$ dis agree that assessment methods and the marks allotted for each method should be written on the course out line to be given for the students. Nonetheless, contrary to what they believe, only $(40 \%, \mathrm{~F}=2)$ instructors do so while majority $(40 \%, \mathrm{~F}=3)$ never write and $(20 \%, \mathrm{~F}=1)$ never gave course outline at all. Further our data show that from instructors who wrote assessment method they would use and the mark should be allotted for each method on the course outline, our document reviewed indicted that only one course $(25 \%, \mathrm{~F}=1)$ has evaluated as such.

It is also worth mentioned that the assessment practices used by instructors of the center was summative in nature and given for students only at the end of each courses. Accordingly, instructors responded $(80 \%, \mathrm{~F}=4)$ that that they only gave an assignment and final exam for students at the end of the course to determine their grade and report to the registrar office at the end of the semesters. The responses of the students also indicated similar trend as majority of the students $(82 \%, \mathrm{~F}=14)$ responded that they have taken assignment and final exam at the end of the courses to get the grade in that course for the next registration.

\subsection{Most frequently Used Assessment Methods in the center for RLDS}

The data collected both from students and instructors indicated that assignment and final exam is frequently used assessment methods. The response from students supporting this idea that final exam and assignment have highest frequency of 16 out of total sample $(\mathrm{N}=17)$ or $94.1 \%$.

When one looks at the response from instructors, it is possible to look at some variation per the academic rank of the instructors, but it is possible to mention that majority of the instructors $(80 \%, \mathrm{~F}=4)$ used assignment and final exam very often. 
Table1: Instructors academic rank * Assessment method most frequently used cross tabulation

\begin{tabular}{|c|c|c|}
\hline & Assessment frequently used & \\
\hline & Assignment and final exam & 10 tal 70 \\
\hline Lecturer & 1 & 20 \\
\hline Ass. Professor & 2 & 40 \\
\hline Professor & 2 & 40 \\
\hline Total & 5 & 100 \\
\hline
\end{tabular}

From the above table, it is clear that there is variation to use assignment and final exam vey frequently depending on the academic rank of instructors as the response from associate professors and professors is much higher $(80 \%$ with $\mathrm{F}=4)$ than that of lecturers $(20 \%$ with $\mathrm{F}=1)$.

When we have a look at the assessment method used very often cross tabulating with years of services in the university we have got very similar trend with the cross tabulation made with assessment method frequently used and academic rank. Thus, as the service years of instructors in the university increased, their commitment to use variety assessment techniques decreased but the inclination to use one or two assessment method increased.

Table 2: Assessment method frequently used by instructors * years of service in university cross tabulation.

\begin{tabular}{|c|c|c|c|c|c|}
\hline Assessment Method frequently & \multicolumn{4}{|c|}{ Years of service in University } & Total \\
\hline used & 4 & 5 & 6 & 10 & \\
\hline Assignment and final exam & 1 & 1 & 1 & 3 & 5 \\
\hline$\%$ & 20 & 20 & 20 & 60 & 100 \\
\hline
\end{tabular}

Even though according to their response majority of instructors from total sample $(\mathrm{N}=5)$ used assignment and final exam frequently as their methods of assessment there is variation among instructors depending on their years of services in university. Accordingly, as it can easily observed from the above table, instructors with lower years of services (years of services $=4,5,6$ respectively) are less inclined $(60 \%, F=1$ for each) to use assignment and final exam more frequently compared to those who have more years of service in university (years of service $=10$ ) and use of these methods $(60 \%, \mathrm{~F}=3)$.

The response on the part of student also significantly support that assignment and final exam are the most frequently used assessment method in the center of RLDS in 2018/09 academic year. The following chart explains this issue clearly.

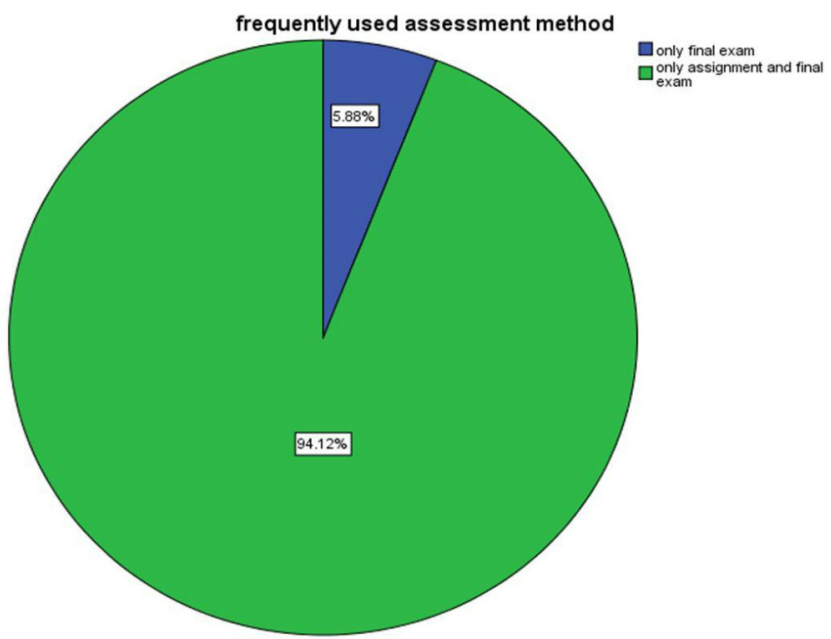

Fig 2. Frequently used Assessment in the center from student's response

The chart shows that only assignment and final exam $(94.12 \%, \mathrm{~F}=16)$ are a common methods of assignment 
while only final exam $(5.88 \%, \mathrm{~F}=1)$ included in students response, but according to the response from the students all other assessment methods completely left out of the set of assessment practices of the center in the academic years in question.

Most commentators show up that student's preference of assessment has its own influence on the instructors' selection of assessment methods. Similarly, our data on students' assessment preferences signifies this concept as shown on the following graph.

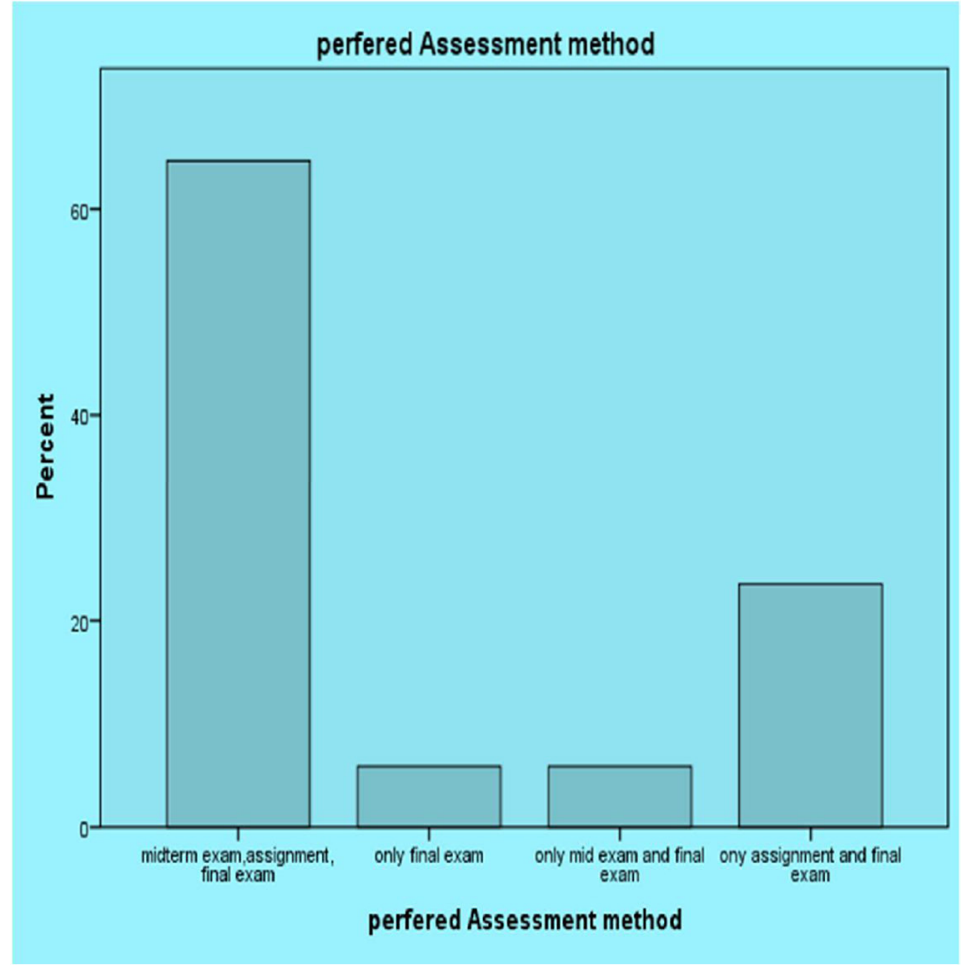

Fig 3: Students assessment method preferences

Thus, even if there was variation in their preferences among students depending on their academic year, the above bar chart reveals that $(64.7 \%, \mathrm{~F}=11)$ of students preferred the combination of mid exam, assignment and final exam, 11.8\% $(\mathrm{F}=2)$ preferred "only final exam" and "only mid and final exam" respectively, whereas the rest $(23.5 \%, F=4)$ choses "only assignment and final exam".

\subsection{The effectiveness of Assessment Methods Used by instructors in RLDS}

In his investigation of the perception and reflection of Indian and Ethiopian faculty members of AAU on students assessment, P.Mohan Raju, (2007) argued that whether students result expectation match with what they actually scored or not has its own implication on the effectiveness of a given assessment methods. Accordingly, this paper found out that many student's $(70.6 \%, \mathrm{~F}=12)$ result expectation mismatched with what they actually scored while only few students $(29.4 \%, F=5)$ result expectation matched with what they actually scored, but there is significant variation between second and first year students.

Further, P.Mohan Raju, (2007), strongly contended that students result expectation match or mismatch with their actual score has implication on how students think about their instructors during evaluation. He clarified that, even though there are other factors, mismatching of students result expectation with their actual score cause students to distrust their instructors during evaluation. Thus, our data signifying this concept, majority of students $(65 \%, \mathrm{~F}=11)$ respond that they mistrust their instructors during evaluation while only small portion of the student respondents $(35 \%, \mathrm{~F}=6)$ respond as they trust their instructors during exams and grading.

The data from the responses of students to our interview questions also supported the same idea. During interview students replied that, they mistrust their instructors because they did not sure how the instructor mark their work and changed to grade. These students further replied that they have no faith of the way instructors change their marks to grades as "their instructors have no culture of displaying their exam and assignment paper", and they even assume that "instructors arbitrarily change their marks to grades without any criteria."

Mistrusting is even more on those students whose expectation mismatched with their actual score, as they have explained on the interview, that the instructors never strictly review their work to mark and changed to grade. For these students, instructors "simply assign grade for students without rigorously correcting and marking the works of students" (i.e. assignment and final exam).

Similar to these the response from students on their perception of the effectiveness of assessment practices 
used by instructors in the center indicated very similar trend. According to this response majority of students $(42.2 \%, \mathrm{~F}=7)$ got the assessment method used by instructors poor.

In addition, there is no significant variation among students depending on their academic year. The following table indicated that the response of first year students who answer the assessment method of their instructor as poor $(41.7 \%, \mathrm{~F}=5)$ is very close to the response of second year students $(40 \% \mathrm{~F}=2)$.

Table 3: Academic year * students perception on assessment employed by instructors cross tabulation.

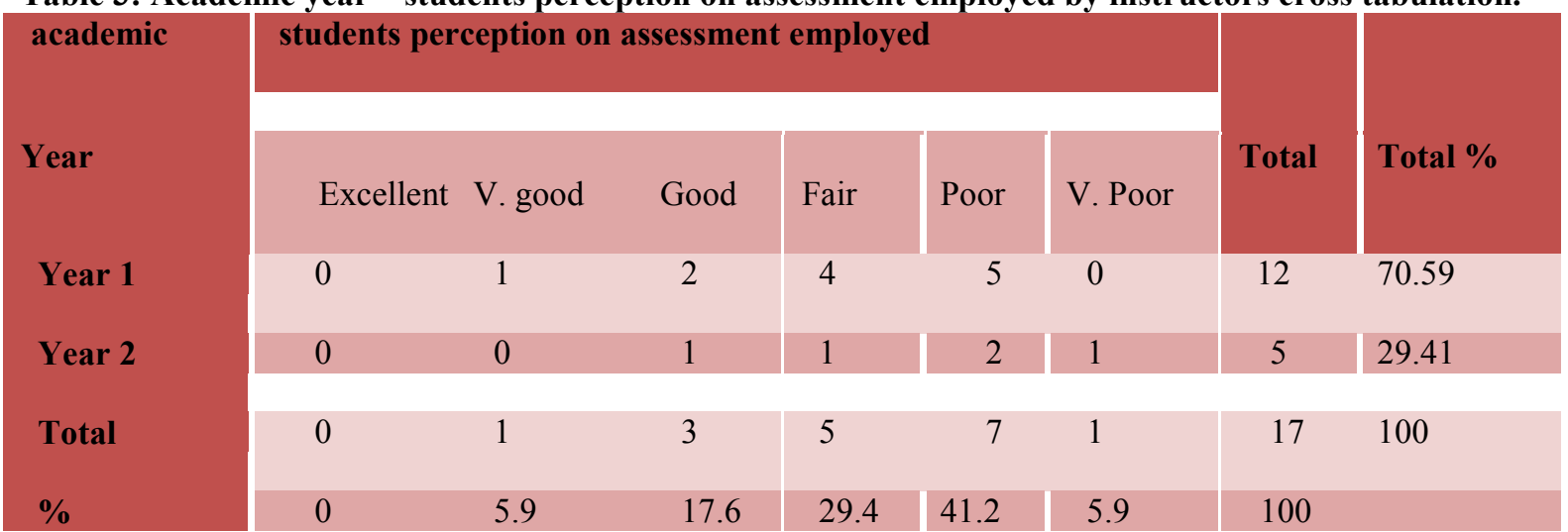

The finding of our research also indicated that even though $(60 \%, \mathrm{~F}=3)$ instructors from total sample believed that training should have power in updating their assessment skill, never the less very absolute majority of them $(100 \%, F=5)$ responded that they never take any training either in general pedagogy or in student assessment techniques since they have employed in the center. Our interview made with instructors also support this idea signaling some reasons why the center not committed to look the way for instructors to get such training. Accordingly, many instructors informed that they think the center believed that they are mature enough having long experience both in teaching and research, hence incurring cost of training is unnecessary.

\section{CONCLUSIONS}

On the bases of the results and discussion drawn from the summarized data, the researchers would like to forward the following conclusions.

It was able to be concluded that it is hardly possible to talk about continuous assessment in the center of RLDS in 2018/09 academic year. In the center assessment is pencil-paper summative exam simply for grading not for students learning and more dangerously the assessment method selection, marking system, item included in exams and grading system are all based on the arbitrary personal wishes of instructors giving lots of pain for students when they got very different grades even assuming their best performance in a given courses.

In addition it is safely possible to conclude that there is no formal way to held instructors responsible for their work whether good or bad because it is not made sured whether guideline that guide instructors assessment practices is available or not and with the same token its hardly possible for students to know how their work marked and changed to grade for there is no mechanism for students to check their result as well as to appeal for correction of even the grade they know incorrect.

The other conclusive issue is that in the center for RLDS, in academic year 2018/09, there is significant variation among instructors in their assessment of students depending on their service year in the university and academic rank. Accordingly the finding significantly indicated that as the academic rank increase from lecturer to professor and as service year increase the inclination of instructors to use one or two assessment method particularly assignment and final exam increases.

Further our findings also helped as to conclude that in the center the efforts done so far in upgrading the assessment skill in particular and the general pedagogical skills of the instructors in general is very weak.

Generally the above conclusion that are drawn from the finding of our study leads us to the overall conclusion that the assessment practices instructors in RLDS of 2018/09 academic year is ineffective and unable to facilitate students learning. Thus, the assessment method employed by instructors in the center was not indicated the academic performance of the students proving that the quality of education is questionable.

\section{RECOMMENDATIONS}

Evaluation process should ensure academic standards of students in higher education. It also needs to carry credibility among the examinees. Thus, to meet these important qualities of higher education's student evaluation methods, assessment practices in the center for RLDS of college of Development Studies in Addis Ababa University should give due concern and cool attention to the following points.

At the beginning, there should be standard assessment guideline that the instructors should refer to assess their students. The guideline should be according to the higher education assessment policy of the country and 
taken in to account the nature of each course thought in the center. In addition, mechanism to follow instructor's assessment system and strategy as well as ways to check the accountability of instructors for their irresponsible way of evaluating their students has to be setup in the center. To this end an independent body may be committee that could follow and supervise the assessment activities of instructors, the efficiency and effectiveness of assessment method used by instructors should be organized. Each module and course should have clear assessment methods, techniques and strategies and, these could be announced to the students at the beginning as well as an independent body which we shall call it assessment committee should follow and supervise whether instructors change to practice or not. The assessment practice of instructors, the marking and grading systems, generally, the assessment activities of instructors should be according to the predetermined principles and rules and should not be arbitrarily depending on subjective personal whims and wishes of instructors.

Secondly, assessment method should be continuous and it should to facilitate students learning not simply for grading. Assessment methods in the center should be both formative to help students to learn more through finding and researching for further information and summative to determine student's performance and success. There should be time break down and time table, as just course break, for assessment of students and, assessment should be carried out according to this break down. Students should be given both group and independent works, variety of assessment methods and items that can assess all cognitive, affective and psychomotor domains of learning should be included in to assessment practices of the instructors of the center. When selecting an assessment methods the combination criteria's such as course objectives, course nature, and teaching methodology as well as students interest and other objective pedagogical criteria should be used not simply one of the criteria's or the subjective interests of instructors like minimizing work load and the like.

Thirdly, teaching profession is dynamic; it depends on time and technology. Experience alone cannot satisfy the knowledge and skills teaching profession deserves. Therefore the center should have policies of professional development and student assessment trainings in particular and pedagogical trainings in general should be given to the instructors. As teaching profession deserve to satisfy what the changing time and technology need, the training should be time wise and should not be once and for all. In addition the center should be give ac careful attention to its recruitment policy, young researchers and lectures should be got attention in the recruitment policy of the center. As our finding empirically justified young instructors has less inclination of using one or two summative paper-pencil exam than older professors. Young lecturers relatively has more commitment to use variety assessment methods than the older professors, thus they has to get enough room during recruitment and course assignment.

\section{REFERENCES}

Abera Assefa (2012) "continuous assessment (CA) vis-à-vis the attainment of major educational domains of physical education in Ethiopia" International Journal of Social Science \& Interdisciplinary Research,1(13),pp.15-16

Airasian PW (1991). Classroom assessment. New York. McGraw-Hill.

Asabe MB (2007). Effects of continuous assessment on academic achievement of NCE. A thesis submitted to the postgraduate school in partial fulfillment of the requirements for the award of the degree of master of education chemistry students in Kaduna state.

Aytaged Sisay (2010).A comparative study on the practice of continuous assessment between Addis Ababa and Unity universities. Academic Journals,8(16),p.1463

Babbie, Earl (1986). The Practice of Social Research (4th ed.). Belmont, California: Wadsworth

Bond LA (1996). Norm- and Criterion-Referenced Testing. Practical Assessment, Research \& Evaluation, 5(2). Retrieved on March 4, 2014 from http://PAREonline.net//getvn.asp?v=5\&n=2.

Brown S, Knight P (1994). Assessing Learners in Higher Education. London: Kogan page Ltd.

Cain M (2012). 'Beliefs about classroom practice: a study of primary teacher trainees in Trinidad and Tobago'. Int. J. Human. Soc. Sci. 2(3):96-105.

Creswell, John W. (2009). Research Design: Qualitative, Quantitative and Mixed Methods Approaches. (3rd ed.). London: SAGE Publications Ltd.

Dagne T (2009). The Exploration of the Practices of Continuous Assessment by EFL Instructors: the Case of Jimma Teachers College (Unpublished MA Thesis).

Dunn L, Parry S, Morgan C (2002). Seeking Quality in Criterion Referenced Assessment. Retrieved on March 6.2014 from http//www.leeds.ac.uk/educol/ documents/00002257.htm.

Ellington H, Earl E (1997). Making effective continuous assessment and portfolios. Glasgow: Glasgow Caledonian University.

Falayalo W (1986). Philosophy and theory of continuous assessment. A paper presented at a workshop for Inspectors of Education in Odor State, Nigeria. 4th December.

FDRE (1994). Education and Training Policy. Ministry of Education, Addis Ababa Ethiopia

Garrison C, Ehringhaus M (2007). Formative and Summative Assessments in the Classroom. Retrieved on March 
10,2014 from http://www.nmsa.org/Publications/.

Gemachu Abera (2013), Assessing Factors Affecting the Implementation of Continuous Assessment in Rift Valley University College with Special Attention to Technical and Vocational Educational Training (TVET) Programs at Adama Main Campus, East Shoa, Oromia Regional State, Ethiopia, East Africa. Adama, Oromia

Juliet OA (2007). A survey of the implementation of continuous assessment in Nigerian universities, a paper presented at second regional conference of higher education research and policy network (herpnet) held at II 1a Ibadan, Nigeria.

Kapambwe WM (2010). 'The implementation of school based continuous assessment (CA) in Zambia,' Retrieved on March 10, 2014 from http://www. academicjournals.org/ERR.

Kellaghan, T. and Greaney, V. (2004) $)^{\text {ceee }}$ Using Examination to improve Education: A study in Fourteen African countries $^{\text {ecee }}$. Washington D.C: world Bank Technical paper No 165.

Kothari, C.R. (2004). Research Methodology: Methods and Techniques. (2nd ed.). New Delhi: New Age International $(P)$ Ltd.

Kumar, Ranjit (1999). Research Methodology: A step-by-Step Guide for Beginners. London: SAGE Publications Ltd.

Muluken, A. (2006).Teachers ${ }^{\text {ee }}$ perception and practices of continuous Assessment in selected Government first cycle primary schools of Addis Ababa. MA Thesis: Addis Ababa University. (Unpublished).

Neuman, Larence W. (1994). Social Research Methods: Qualitative and Quantitative Approaches (2nd ed.). Bosto: Allyn and Bacon.

Nitko AJ (2004). 'Continuous assessment and performance assessment.' Retrieved March. 11, 2014 from http://www. moec.gov.jm.pdf. Publishing Co.

Punch, Keith F. (1998) Introduction to Social Research: Quantitative and Qualitative Approaches. London: SAGE Publications Ltd.

TGA (1994). Education and Training Policy. Ministry of Education, Addis Ababa Ethiopia.

Yizengaw, T., 2003, 23-25 September, Transformations in Higher Education: Experiences with Reform and Expansion in the Ethiopian Higher Education System. Accra, Ghana.

\section{$\underline{\text { Appendix } 1}$}

\section{Questionnaire for Instructors}

\section{PURPOSE}

This questionnaire is designed to collect relevant information about your views on the systems and practices of Assessment in center for Regional and Local Development Studies. Your response to the items of this questionnaire will remain confidential and the results will be used to examine the existing Assessment practices at the center. We hope you will be able to take time and carefully complete this questionnaire. You can circle from the given choices to indicate your responses for items with alternative responses. Please briefly state your responses for the open - ended items.

Thank you in advance for your time!

\section{General}

1. Age

2. Sex 1 Male

3. Educational Qualification

2. Female
1. M.A/MSc
2. Ph. D 3. Others (specify)

4. Academic rank 1. Lecturer 2. Assistant Professor 3. Associate Professor 4. Professor 5. Others (please specify)

5. Year/s of service in University

\section{Assessment Practices}

1. Do you think that the assessment technique used so far was enough in evaluating of the students?

2. If the answer for the above question is No, what are the reasons for it? 
3. Is there a general guideline for assessment practices issued by the university, college or

$$
\text { 1. Yes }
$$

2. No

4. If your Answer for question number 3 is yes, did you refer to these guidelines to evaluate your students when gave a course for RLDS students?
1. Yes
2. No

5. If your Answer for question number 4 is No, please state major reasons 28

6. Have you taken any training on student assessment techniques or any pedagogical training?
1. Yes
2. No

7. Do you think is that necessary and useful to have training on student assessment techniques?
1. Yes
2. No

8. Which Assessment Method you have frequently used?

1. Midterm exam, Assignment, final examination

2. Only final exam

3. Only midterm exam and final exam

4. Only assignment and final exam

5. Only assignment

6. Others (please specify)

9. How did you assign mark for those assessment methods you have used?

1. Based on university, college or the center's guideline

2. As you wish based on your own criteria

3. Based on student inters

4. Others (please specify)

10. How much marks you have allotted for the following assessment methods on the last course/s you have given for RLDS students?
1. Attendance
2. Quiz
3. Midterm exam
4. Assignment
5. Final exam
6. Others (please specify)

11. Have you ever sent RLDS students to field or given any practical work and taken assessment?

12. If your response for question number 11 is yes, how did you allot marks for such assessment?

1. Directly observing when students perform the work

2. Ordering students to prepare a report on their work

3. Ordering students to bring their performance evaluation from the organization they have assigned to practical work

4. Combination of all of the above

5. Combination of some of the above, please specify

6. Others (please, specify)

13. What did you think strongly discourage instructors to use an assessment method that can match the expectation of their students?
1. Large class size
5.Teaching method they followed
2. Student's interest
6. Combination of the above
3. Work load
7. Combination of some of the above, please specify 
4. Curriculum/ nature of the course teach
8. Others (please specify) they

14. What criteria do you think the instructors wish to refer when you choose and prepare an assessment method for their students?
1. Meeting the course objectives
3. Helping students easily pass the course
2. Minimizing work load
4. Others (please specify)

15. To what extent do you agree that instructors should write all their assessment method and the marks they allotted for each method on the course syllabus and provide to the students to assess their students so?
1. Strongly agree
3. Disagree
2. Agree
4. Strongly disagree

16. Did you write an assessment you wish to use and the respective mark you want to allot to all assessment methods on the course syllabus and provide to your students, and evaluate your students as per what you have planned on the syllabus?
1. Yes
2. No

17. If your response for question number 16 is No, please specify the reason

\section{Appendix 2}

\section{Questionnaire for Students}

\section{PURPOSE}

This questionnaire is designed to collect relevant information about your views on the systems and practices of Assessment in center for Regional and Local Development Studies. Your response to the items of this questionnaire will remain confidential and the results will be used to examine the existing Assessment practices at the center. We hope you will be able to take time and carefully complete this questionnaire. You can circle from the given choices to indicate your responses for items with alternative responses. Please briefly state your responses for the open - ended items.

Thank you in advance for your cooperation and time!

\section{General}

1. Age

2. Sex 1. Male

2. Female

3. Year 1. First year

2. Second year

\section{Assessment Practices}

1. How do you get the assessment techniques mainly employed by instructors at the center for RLDS?
1. Excellent
2. Very good
3. Good
4. Fair
5. Poor 6. Very poor

2. Do you think that all instructors use the same assessment technique? 1. Yes

3. Among the assessment technique used by your instructors which one you prefer?
1. Midterm exam, Assignment,
final examination
4. Only assignment and final exam

2. Only final exam

5. Only assignment

3. Only midterm exam and final exam

6. Others (please specify)

4. Which assessment techniques your instructors used frequently? 31
1. Midterm exam, Assignment, final examination
4. Only assignment and final 
exam

2. Only final exam

5. Only assignment

3. Only midterm exam and final exam

6. Others (please specify)

5. Do you think the assessment method used by your instructors matched your expectation?

6. If your answer for question number 5 is No, What should be done do you think to make assessment method match your expectation?

7. To what extent did you agree that students generally mistrust their instructors during evaluation?

1. Strongly agree

2. Disagrees
3. Agree

4. Strongly disagree

8. Have you trust your instructors on how they evaluate you and determine your grade for the courses they have thought you?
1. Yes
2. No

9. If your answer for question number 8 is No, state major reasons.

10. If you think that the assessment method used by instructors at the RLDS is not good, what do you think should be done?

\section{Appendix 3}

\section{Interview for Instructors}

1. Have ever given a course for either second or first year RLDS students?

2. Have you any part time work? If so, can you suggest us the place of such your work?

3. What opportunities have you had to bring variety of assessment method for your students?

4. How well has your university help you to develop your teaching profession?

5. Can you describe the teaching techniques or strategies that are most effective for you?

6. Are you giving a consultancy service or any other community service outside Addis Ababa University?

7. How would you include cooperative learning in your classroom?

8. What would you do if $50 \%$ of your class did poorly on a test?

9. How do you deal with the unmotivated student? 
10. What curricular changes do you hope to see over the next few years?

11. What do you think makes you an effective teacher?

12. What do you feel that students expected from their instructors during evaluation?

13. Do you feel that instructors should responsible for developing assessment methods as they wish or should they provided by their university, college or department?

14. What do you suggest to alleviate existing problems at center for RLDS in assessing of students?

\section{Appendix 4}

\section{Interview Questionnaire for RLDS Students}

1. What types of assessment technique should instructors used?

2. How do you see the assessment techniques mainly practiced so far by instructors?

3. Are you interested by the techniques of assessment that the instructors have using?

4. What are the main problems have been observed in assessing of students?

5. What needs to be done for the future in order to evaluate students effectively?

\section{Appendix 5}

\section{Desk Review}

1. What look like the question papers and evaluation results of students?

2. What looks like the final assessment results of each student? 